Spontaneous intracystic hemorrhage complicating an intracranial arachnoid cyst

Sir,

Chronic subdural hematoma (CSDH) generally occurs in elder people and is uncommon in the young. Arachnoid cysts are considered as a risk factor for CSDH in young patients. ${ }^{[1]}$ Arachnoid cysts are usually asymptomatic, but can become symptomatic because of cyst enlargement or hemorrhage either following mild head trauma or spontaneously. ${ }^{[2]}$ Association of arachnoid cysts with CSDH in the absence of head trauma is very rare and with spontaneous intracystic hemorrhage even rarer. ${ }^{[3]}$ We report a case of arachnoid cyst associated with spontaneous intracystic hemorrhage and CSDH. A 12-year-old boy was admitted to casualty with a short duration history of a headache, projectile vomiting, fever, and altered sensorium. There was no history of trauma. On examination, he was febrile and drowsy with a Glasgow Coma Score of $13 / 15$. There were terminal neck stiffness and no focal neurological deficits. With a provisional diagnosis of meningitis/encephalitis computed tomography of the brain was done as a routine before attempting a lumbar puncture. Computed tomography showed left frontotemporoparietal CSDH with gross midline shift and few areas of contrast enhancement [Figure 1]. A left frontotemporoparietal craniotomy was done

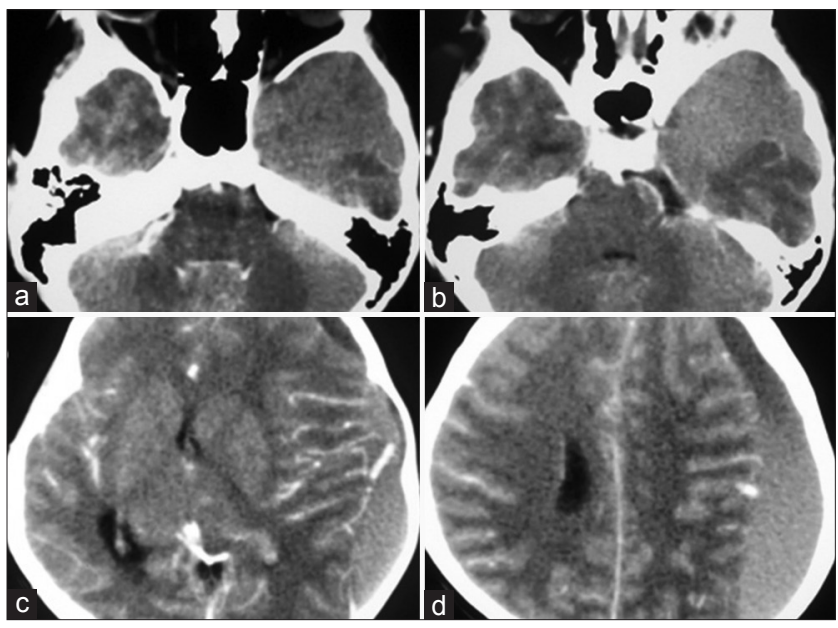

Figure 1: Contrast enhanced computed tomography showed left chronic subdural hematoma completely occupying temporal fossa ( $a$ and $b$ ), fronto parietal regions with gross midline shift and few areas of contrast enhancement (c and d) and on opening the dura mater, there was a subdural collection of blood [Figure 2a]. After clearing the subdural blood, a cyst was occupying the left temporal pole and sylvian fissure [Figure $2 b$ and $c$ ]. The cyst had hemorrhagic fluid which was evacuated, and the total excision of the cyst wall was done [Figure 2d]. The patient tolerated the procedure well and recovered completely. The histopathology of the excised cyst wall was consistent with arachnoid cyst [Figure 3]. Arachnoid cysts are extra cerebral and intra-arachnoidal cerebrospinal fluid collections that comprise $1 \%$ of all nontraumatic intracranial mass lesions. ${ }^{[1]}$ Modern imaging modalities have increased the detection of incidental asymptomatic arachnoid cysts. ${ }^{[2]}$ Very rarely, such incidental asymptomatic cysts can become symptomatic because of cyst enlargement or hemorrhages. ${ }^{[3]}$ Davidoff and Dyke in 1938 reported the first association of arachnoid cyst with intracystic hemorrhage and $\mathrm{CSDH} \cdot{ }^{[3]}$ Arachnoid cysts are sometimes associated with subdural effusions which may result from tearing off the outer wall of the cyst secondary to either trauma or spontaneous rupture. ${ }^{[2]}$ The pathogenesis of intracystic and subdural hemorrhage has been attributed to rupture of bridging veins, unsupported blood vessels around the cyst wall, and leptomeningeal vessels at the base of the cyst ${ }^{[2]}$ secondary to the cyst wall tear. Spontaneous rupture may result from the gradual enlargement of the cyst due to the production of fluid from the cyst walls. ${ }^{[2]}$ On imaging, an intracystic hemorrhage may mask the presence of an arachnoid cyst making it difficult to distinguish an arachnoid cyst from a sub-acute or chronic intracystic or subdural hemorrhage. On reviewing the literature, an intracystic bleeding complicating arachnoid cysts have been reported

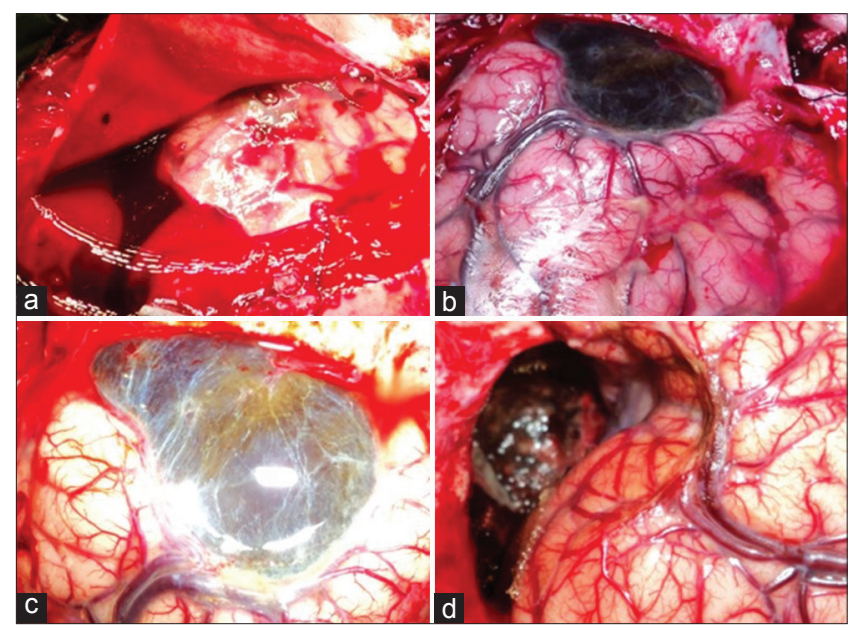

Figure 2: Intraoperative photographs showing collected subdural blood after opening the duramater (a), arachnoid cyst occupying the temporal pole and sylvian fissure before (b and c) and after (d) excision 

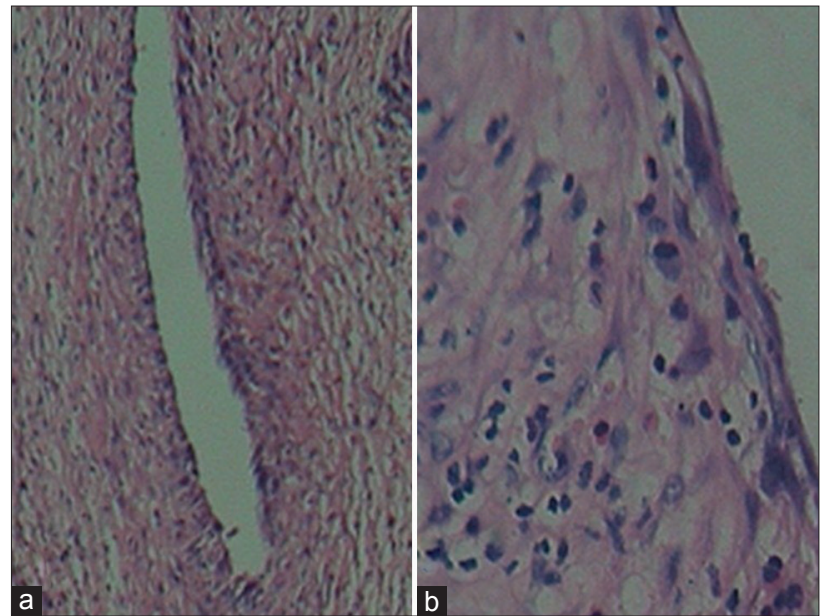

Figure 3: Microphotograph, $\mathrm{H}$ and $\mathrm{E}$ stain $\times 10$ (a) and $\times 40$ (b) the cyst wall lined by flattened to cuboidal cells supported by collagen

in less than forty cases, and spontaneous rupture causing hemorrhage has been reported only in nine cases. ${ }^{[3]}$ The best modality of treatment for patients with an arachnoid cyst and hemorrhage is surgery which includes hematoma evacuation and radical marsupialization. ${ }^{[2]}$ Surgical outcome is favorable with recurrence being unusual following such radical treatment. ${ }^{[3]}$ The diagnosis of a hemorrhage superposed on an arachnoid cyst can be tricky. It is important to identify and report such rare complications and asymptomatic patients with an incidental arachnoid cyst should be counseled about such possibilities.

\section{Financial support and sponsorship}

Nil.

\section{Conflicts of interest}

There are no conflicts of interest.
V. V. Ramesh Chandra, B. Chandramowliswara Prasad, C. Siva Subramanium, Ravi Kumar

Department of Neurosurgery, SVIMS, Tirupati, Andhra Pradesh, India

Address for correspondence: Dr. V. V. Ramesh Chandra Department of Neurosurgery, SVIMS Tirupati - 517 507, Andhra Pradesh, India. E-mail: rcvvns@gmail.com

\section{References}

1. Mori K, Yamamoto T, Horinaka N, Maeda M. Arachnoid cyst is a risk factor for chronic subdural hematoma in juveniles: Twelve cases of chronic subdural hematoma associated with arachnoid cyst. J Neurotrauma 2002;19:1017-27.

2. Galassi E, Piazza G, Gaist G, Frank F. Arachnoid cysts of the middle cranial fossa: A clinical and radiological study of 25 cases treated surgically. Surg Neurol 1980;14:211-9.

3. Davidoff LM, Dyke CG. Relapsing juveline chronic subdural haematoma: A clinical and roentgenographic study. Bull Neurol Inst NY 1938;7:95-111.

This is an open access article distributed under the terms of the Creative Commons Attribution-NonCommercial-ShareAlike 3.0 License, which allows others to remix, tweak, and build upon the work non-commercially, as long as the author is credited and the new creations are licensed under the identical terms.

\begin{tabular}{|l|l|}
\hline \multicolumn{2}{|c|}{ Access this article online } \\
\hline Quick Response Code: & Website: \\
\hline & www.ruralneuropractice.com \\
\cline { 2 - 2 } & \\
\hline
\end{tabular}

How to cite this article: Chandra VR, Prasad BC, Subramanium CS, Kumar R. Spontaneous intracystic hemorrhage complicating an intracranial arachnoid cyst. J Neurosci Rural Pract 2015;6:629-30. 